\title{
(6) OPEN ACCESS \\ Randomised controlled trial evaluation of Tweet2Quit: a social network quit-smoking intervention
}

\author{
Cornelia Pechmann, ${ }^{1}$ Kevin Delucchi, ${ }^{2}$ Cynthia M Lakon, ${ }^{3}$ Judith J Prochaska ${ }^{4}$
}

\begin{abstract}
- Additional material is published online only. To view please visit the journal online (http://dx.doi.org/10.1136/ tobaccocontrol-2015-052768)

${ }^{1}$ The Paul Merage School of Business, University of California Irvine, Irvine, California, USA 2Department of Psychiatry, University of California San Francisco, San Francisco,

California, USA

3Program in Public Health, University of California Irvine, Irvine, California, USA ${ }^{4}$ Department of Medicine, Stanford Prevention Research Center, Stanford University, Stanford, California, USA
\end{abstract}

\section{Correspondence to}

Dr Cornelia Pechmann, The Paul Merage School of Business, SB1-4317, University of California, Irvine, CA 92697 USA; cpechman@uci.edu

Received 15 October 2015 Accepted 10 February 2016 Published Online First 29 February 2016

\begin{abstract}
Background We evaluated a novel Twitter-delivered intervention for smoking cessation, Tweet2Quit, which sends daily, automated communications to small, private, self-help groups to encourage high-quality, online, peer-to-peer discussions.
\end{abstract}

Design A 2-group randomised controlled trial assessed the net benefit of adding a Tweet2Quit support group to a usual care control condition of nicotine patches and a cessation website.

Participants Participants were 160 smokers (4 cohorts of 40/cohort), aged $18-59$ years, who intended to quit smoking, used Facebook daily, texted weekly, and had mobile phones with unlimited texting.

Intervention All participants received 56 days of nicotine patches, emails with links to the smokefree.gov cessation website, and instructions to set a quit date within 7 days. Additionally, Tweet2Quit participants were enrolled in 20-person, 100-day Twitter groups, and received daily discussion topics via Twitter, and daily engagement feedback via text.

Measures The primary outcome was sustained abstinence at 7, 30 and 60 days post-quit date.

Results Participants (mean age 35.7 years, 26.3\% male, 31.2\% college degree, $88.7 \%$ Caucasian) averaged $18.0(S D=8.2)$ cigarettes per day and $16.8(S D=9.8)$ years of smoking. Participants randomised to Tweet2Quit averaged 58.8 tweets/participant and the average tweeting duration was 47.4 days/participant. Tweet2Quit doubled sustained abstinence out to 60 days follow-up $(40.0 \%, 26 / 65)$ versus control $(20.0 \%, 14 / 70), 0 R=2.67$, $\mathrm{Cl} 1.19$ to $5.99, p=0.017$. Tweeting via phone predicted tweet volume, and tweet volume predicted sustained abstinence $(p<0.001)$. The daily autocommunications caused tweeting spikes accounting for $24.0 \%$ of tweets. Conclusions Tweet2Quit was engaging and doubled sustained abstinence. Its low cost and scalability makes it viable as a global cessation treatment.

Trial registration number NCT01602536.

\section{BACKGROUND}

Social network sites, defined as web-based services that allow individuals to construct user profiles, communicate with others with whom they share a connection, and view others' communications, ${ }^{1}$ would seem to be an ideal forum for self-help groups. ${ }^{2-7}$ Social network sites are popular, virtually cost-free, accessible on laptops and mobile devices, and highly interactive. $^{8} 9$ In the USA, 73\% of online adults report using social network sites, such as Facebook or Twitter, with $42 \%$ using multiple sites, often daily. ${ }^{10}$

Social network sites' potential for facilitating selfhelp groups is still unrealised, though. Similar to predecessor technologies, such as bulletin boards and listservs, prolonged engagement is often poor; initial interest may be high but often wanes. ${ }^{2} 11-13$ Research has identified three main reasons for this. ${ }^{14-17}$ People do not see and/or respond to others' posts promptly enough, causing dropouts. ${ }^{17}$ New members' posts may be ignored because they lack social capital within the group. ${ }^{16}{ }^{18}$ Even active members gradually lose interest and disengage, and thus most groups have a limited duration. ${ }^{14}$

We developed a novel intervention for smoking cessation called Tweet2Quit that seeks to address these limitations. Tweet2Quit sends twice-daily automated communications ('autocommunications') to encourage frequent and concurrent check-in, forms small intimate groups that start immediately and are closed to new members, and is purposefully of limited duration. Tweet2Quit builds on promising past work in buddy interventions, in which smokers were assigned physically proximal quit buddies. ${ }^{19-21}$ With Tweet2Quit, smokers meet numerous potential quit buddies in a virtual online forum. Research on Tweet2Quit can provide valuable insights about the utility of extratreatment (ie, peer-based) social support for smoking cessation, because studies on this topic have been limited, and results have been mixed. ${ }^{19} 22$

Tweet2Quit also builds on promising research on health interventions that employ autocommunications, that is, text or email messages from health experts that are sent automatically to participants to encourage healthy behaviours. ${ }^{23-27}$ At least 13 randomised controlled trials of autocommunication-based interventions for smoking cessation have been conducted, and the results have been promising. ${ }^{23} 25$ The results also suggest that fixed message schedules perform better than decreasing or variable schedules, ${ }^{28}$ so Tweet2Quit uses a fixed schedule.

Tweet2Quit is, in effect, a hybrid intervention that involves both: (1) social network-based, peer-to-peer participant exchanges and (2) daily autocommunications sent by the study website posing treatment-relevant questions from experts for participants to discuss. Our research hypothesis was that Tweet2Quit would significantly increase sustained abstinence, defined as 7-day point prevalence abstinence at 7,30 and 60 days post-quit date, ${ }^{29-31}$ relative to a usual care-control condition.

\section{METHODS}

\section{Study design}

A 2-group randomised controlled trial was conducted to assess the net benefit of adding Tweet2Quit to a usual care control condition. The 
study was conducted in four cohorts of 40 participants (total $\mathrm{N}=160$ ). Once 40 individuals were screened as eligible, they were individually assigned using computer-generated 1:1 randomisation to Tweet2Quit or the control condition. All participants received study-provided nicotine patches and referral to the smokefree.gov smoking cessation website. Those receiving the Tweet2Quit intervention were assigned to 20-person, 100-day support groups on Twitter, in which smokers supported each other to quit, encouraged and directed by twice-daily autocommunications.

It took about 4 months to enrol each of our four cohorts of 40 persons. Recruitment and interventions occurred in 20122013, and data were analysed in 2014-2015. The trial sample size $(\mathrm{N}=160)$ was based on a power analysis informed by autocommunication-based smoking cessation trials (details in online supplementary material).

\section{Study sample and recruitment}

A national sample of US smokers was recruited using the Google search engine and a US\$10 000/month advertisement budget on Google AdWords (see online supplementary material for details). If smokers were interested in participating, they completed a brief online interest form requesting their email. Then about 1 month before a projected cohort start date, they were emailed a link to our screening survey to assess their eligibility and obtain informed consent. Inclusion criteria were: resident of the continental USA, English speaking, aged 18-59 years, smoked 100+ cigarettes in lifetime, currently smoking $\geq 5$ cigarettes daily, intention to quit smoking in the next month, active email account, mobile phone with internet access and unlimited texting, weekly texting, and daily Facebook use. The age range was $18-59$ years to be as inclusive as possible, while excluding two age groups that were likely to have different lifestyles and cessation motivations: minors for whom cigarette use is illegal and retired older adults.

Exclusion criteria were: health contraindications to nicotine patch use; actively taking medication for depression, anxiety or quitting smoking; illicit hard drug use in the past 4 weeks; daily marijuana use; residence with another participant; failure to provide contact or collateral information; and/or failure to respond to a confirmatory text sent to their mobile phone. Our university IRBs approved the research and participants consented online.

In our Tweet2Quit pilot study, we found that daily Facebook use was significantly correlated with engagement in Tweet2Quit, while prior Twitter use was uncorrelated. ${ }^{32}$ Hence, for this clinical trial, we required daily Facebook use, not Twitter use. Nevertheless, we used Twitter as our technology platform because, at the time, Facebook periodically changed its default privacy settings without informing users, so we could not ensure participants' privacy on Facebook. Also, our website firm required Twitter's programming language (API) to set up a website that would automate message delivery and downloading of posts; Facebook's API was inadequate.

\section{Shared treatment components}

Once a cohort was formed, we gave all participants study website accounts using usernames and passwords provided at screening. On the cohort's official start date, all participants were emailed instructions asking them to log into their study website account and set a quit date within 7 days of the start date. While clinical practice guidelines suggest setting a quit date within 14 days of intervention start, ${ }^{22}$ our pilot testing $(\mathrm{N}=40)$ showed that Tweet2Quit participants who delayed setting their quit date until the second week also delayed engaging with their groups, and were marginalised. ${ }^{32}$ Hence, our shift to a 7-day quit window.

Also about a week before their cohort's official start, participants received by mail a 56-day supply of nicotine patches that was dosed per their baseline smoking level (starting with $14 \mathrm{mg}$ patches if $<10$ cigarettes/day and $21 \mathrm{mg}$ patches if $>10$ cigarettes/day). ${ }^{22}$ On their cohort start date, an automated email encouraged participants to select a quit date and to start using the patches on that date. Participants were also encouraged to access smokefree.gov, the National Cancer Institute's quit-smoking website. Automated emails sent smokefree.gov module links as follows: day 1: Prepare to Quit, Quit date +4 days: Quitting, day 8: help line/live chat, Quit date +13 days: Staying Quit, and day 22: help line/live chat. Our study website included the same smokefree.gov links.

\section{Tweet2Quit intervention}

Unique to the intervention condition was enrolment in a Tweet2Quit 20-person, 100-day, virtual peer support group. The groups were closed in that each member followed and was followed exclusively by other members, and no new members were added. The groups were private, because only the group members and the study staff could see the tweets. Twenty smokers were included per group, because, based on marketing research, the average social network has about 17-20 active participants. ${ }^{33} 34$ When we proposed to develop and test our intervention, we expected it to last 60 days but, in our two pilot groups, we let participants tweet as long as they liked, and they tweeted for close to 100 days. Hence, for the subsequent randomised controlled trial, the intervention duration was set at 100 days.

A few weeks before each cohort's start, we set up the Tweet2Quit participants with new Twitter accounts, using the same emails and passwords as their study website accounts. We set up new Twitter accounts to ensure the groups were private, and as a safeguard so that we could close down an account if problematic tweeting occurred, though it never did. No participant complained about having to use a new Twitter account.

Then, at the start of each cohort group, Tweet2Quit participants were sent an automated email that encouraged but did not require them to start tweeting their group at least daily. They were also emailed instructions to set up their mobile phones to send and receive the tweets as texts because this required physical access to their phones. At the time of our study, Twitter users could not set up detailed user profiles, but an automated email encouraged, though did not require, them to post an image or picture that represented them. Tweet2Quit participants often directed their tweets to one or more specific group members using the@sign; however, Twitter automatically sent each tweet to every group member, and the tweets permanently showed up on the group's Twitter feed in chronological order showing sender, date and time.

Tweet2Quit participants also received daily discussion-topic automessages and daily engagement autofeedback for 100 days, using fully automated programmes that ran on our study website. The discussion topic automessages were sent out at 17:00 Pacific (20:00 Eastern), worded as questions, and posted as tweets on the group's Twitter feed. One hundred messages were developed by the research team based on clinical practice guidelines. $^{22} 323536 \mathrm{~A}$ separate paper describes the messages and identifies those that supported behaviour change. ${ }^{32}$

At 9:00 Pacific (12:00 Eastern), participants received individualised autofeedback on their prior $24 \mathrm{~h}$ tweeting. This was sent via a text to each participant's mobile phone to reach those 
not logging into Twitter. A custom programme automatically downloaded the tweets every night, identified tweeters and nontweeters, and sent texts with varied wording. Tweeters were praised (eg, 'Great job staying connected with your quit smoking group. Your tweets make a difference!'), while nontweeters were encouraged (eg, 'Missed hearing from you yesterday! Share how you are doing with your group').

\section{Measures}

The online screening survey assessed participants' eligibility, sex, ethnicity, marital status, education, employment and cigarettes smoked; and obtained contact information including mailing address. An online baseline survey followed randomisation, and measured years smoked, spousal smoking, past quit attempts, past cessation aids, current abstinence goal, ${ }^{37} 38$ and Fagerström Cigarette Dependence. ${ }^{39} 40$ Abstinence surveys were administered at 7, 30 and 60 days post-quit date, as specified in our funded proposal (survey completion rates in online supplementary material), assessing 7-day point prevalence abstinence based on two standard questions: 'How many cigarettes have you smoked in the past 7 days?' and 'Have you puffed on a cigarette within the past 7 days? ${ }^{29} 31$ These questions were emailed and texted to participants and, if there was no response, they were called. The assessment texts came from a different account and at a different time from the study autocommunications, and participants were told the assessment data would be kept confidential.

Sustained abstinence was recorded if a participant responded to the 7,30 and 60 day surveys, and consistently (across both questions) reported 7-day point prevalence abstinence, that is, not smoking for the prior 7 days. ${ }^{29-31}$ Sustained abstinence was the designated end point because it was the more rigorous end point, and the sample was recruited as motivated to quit. ${ }^{41}$ Non-sustained abstinence was recorded if a participant reported smoking on any survey, regardless of the number of surveys completed, otherwise, lost to follow-up was recorded $(25 / 160$, $15.6 \%)$. The timing of the abstinence surveys was based on the quit dates that participants had recorded on the study website. If no quit date was recorded, the last possible date was used.

Supplemental online surveys at 7,30 and 60 days post-quit date measured how many days participants used nicotine patches, and how many times they visited smokefree.gov (survey completion rates are in the online supplementary material). Tweet2Quit tweeting methods (eg, phone, computer) were also assessed among intervention participants. Setting a quit date and posting an image for the Tweet2Quit user profile were determined visually on the study website.

Finally, tweets were automatically downloaded daily into a database that listed each tweet, the date and time sent, the verbatim message sent, the sender's username, and each recipient's username if designated (eg, by @). Engagement, measured at the participant level, was assessed using three metrics: (1) tweet volume (ie, number of tweets each participant sent); (2) days of tweeting (ie, number of days a participant sent at least one tweet) and (3) tweeting duration, which compared the participant's very first and last tweet dates.

\section{Statistical analyses}

Abstinence outcomes were analysed using generalised linear modelling with generalised estimating equations to account for clustering effects of cohorts (Proc Genmod, SAS V.9.3). The first model estimated the effect of condition (intervention vs control) on sustained abstinence after adjusting for cohort, and the interaction of condition-by-cohort. Point prevalence abstinence over time was modelled similarly, but with assessment point as an added factor (7, 30 or 60 days). A third multivariate model estimated the effects of demographic and tobacco use variables on sustained abstinence after adjusting for condition, cohort and condition-by-cohort. Cohort was included because of variability in cohort activity and engagement. The primary outcome, sustained abstinence, included all randomised participants with complete data (figure 1). Twenty-five participants $(15.6 \%, 25 / 160)$ were missing abstinence data at one or more follow-ups. Secondary analyses examined sustained abstinence with these 25 participants lost to follow-up imputed to be smoking. ${ }^{41}{ }^{42}$ Additionally, we analysed the 7 -day point prevalence abstinence rates at each follow-up (ie, at 7, 30 and 60 days post-quit date).

Two additional multivariate models used data from Tweet2Quit participants only to examine mediators of treatment effects. One model estimated the effects of tweet volume and other tweeting-related variables on abstinence. A second model estimated the effects of demographic, tobacco use and tweeting-related variables on tweet volume. Both models adjusted for cohort. Variables with limited variability or high correlations with other variables were not included in these models.

\section{RESULTS}

\section{Study participants}

A total of 614 people completed the online interest form and were sent the screening survey; 444 (72.31\%) did not meet the inclusion criteria, 10 were excluded because enrolment was closed, and 160 were randomised to condition (figure 1). Participants' average age was 35.7 years $(\mathrm{SD}=9.9), 26.3 \%(42 /$ $160)$ were male, $31.2 \%(50 / 160)$ had a college degree or higher, and $88.7 \%(142 / 160)$ were Caucasian non-Hispanic. Of the $51.2 \%(82 / 160)$ who were married or partnered, $47.6 \%(39 / 82)$ lived with a current smoker. At baseline, participants averaged $18.0(\mathrm{SD}=8.2)$ cigarettes daily, had smoked for $16.8(\mathrm{SD}=9.8)$ years, had a moderate Fagerström score of $4.7(\mathrm{SD}=2.1)$, and reported a median of 4 (IQR: $3-7$ ) prior quit attempts of $1+$ days. Most $(67.6 \%, 94 / 139)$ had a resolute abstinence goal: I want to quit smoking once and for all, and never smoke ever again. Table 1 provides additional details.

\section{Sustained abstinence}

Analysis of complete cases indicated sustained abstinence out to 60 days post-quit date of $40.00 \%(26 / 65)$ in the Tweet2Quit condition versus $20.00 \%(14 / 70)$ in the control condition, $\mathrm{OR}=2.67$, CI 1.19 to $5.99, \mathrm{p}=0.017$ (table 2). In an analysis with incomplete cases, imputing participants lost to follow-up as smoking, ${ }^{41}$ sustained abstinence was $32.50 \%(26 / 80)$ for Tweet2Quit versus $17.50 \%$ (14/80) for control, OR=2.27, CI 1.04 to $4.97, p=0.039$. In both analyses, there was a consistent effect for Tweet2Quit versus control across cohorts.

Analysis of 7-day point prevalence abstinence rates over time also showed a significant effect for condition that favoured Tweet2Quit over control, OR=1.89, CI 1.10 to $3.25, \mathrm{p}=0.021$. Imputing lost to follow-up as smoking, the point prevalence abstinence rates at 7,30 and 60 days post-quit date were $41.25 \%(33 / 80), 57.50 \%(46 / 80)$ and $55.00 \%(44 / 80)$ for Tweet2Quit, versus $37.50 \%(30 / 80), 38.75 \% \quad(31 / 80)$ and $41.25 \%(33 / 80)$ for control, respectively.

\section{Treatment usage}

A quit date was set by $81.3 \%(130 / 160)$ of participants, with no difference by condition $(p=0.105)$. Over a third $(37.5 \%, 60 /$ 
Figure 1 Trial profile as a consort flow diagram.

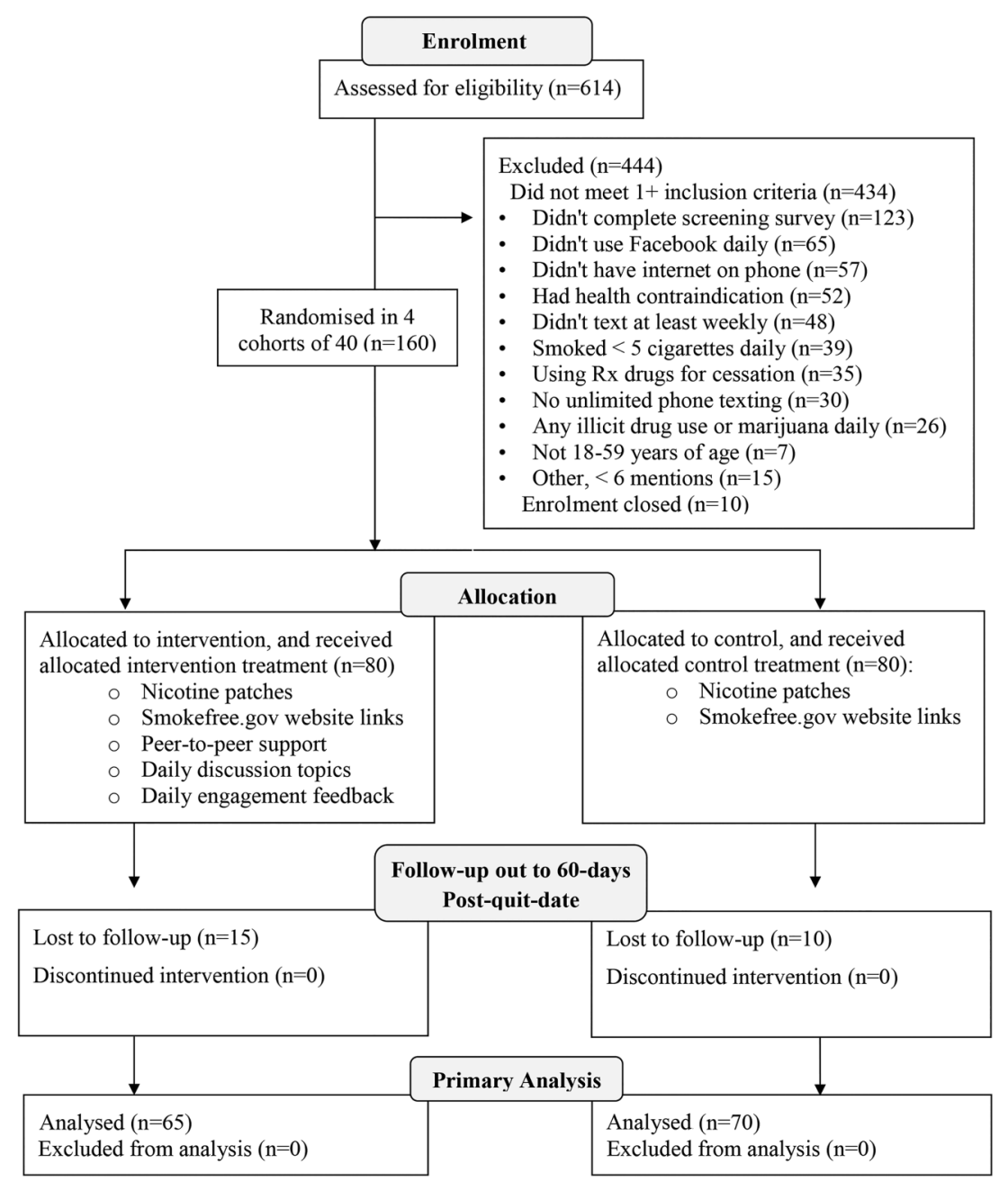

$160)$ of participants chose day $1,31.9 \%$ (51/160) chose days $2-$ 7 and $30.6 \%(49 / 160)$ chose or were assigned the last day. Of the 30 participants who failed to set a quit date, only one reported sustained abstinence. At 7 days post-quit date, 95.1\% (97/102) of participants reported using the nicotine patch at least once, and 35.3\% (36/102) reported visiting the smokefree. gov website at least once (detailed in table 2).

\section{Tweeting behaviours}

Among Tweet2Quit participants, 53.8\% (43/80) posted an image for their user profile, 67.2\% (39/58) reported tweeting on a mobile phone using texting, and $75.9 \%$ (44/58) reported tweeting at work. Three-quarters (60/80) of Tweet2Quit participants tweeted at least once, and total tweets per group averaged $1177(\mathrm{SD}=275$, range $=825-1489)$. On average, each Tweet2Quit participant sent 58.8 tweets $(\mathrm{SD}=68.1$, range $=0$ 324 , median $=34.5$ ), tweeted for a duration of 47.4 days from first to last tweet $(\mathrm{SD}=38.9$, range $=0-95$, median $=47.5)$, and tweeted on 22.9 different days $(\mathrm{SD}=24.0$, range $=0-87$, median=16.0). Each Tweet2Quit participant who tweeted at least once $(\mathrm{N}=60)$ sent on average $78.4(\mathrm{SD}=68.1)$ tweets, for a duration of 63.2 days $(\mathrm{SD}=31.7)$, and on $30.3(\mathrm{SD}=23.4)$ different days.

The daily Tweet2Quit autocommunications caused tweeting spikes within an hour after delivery that accounted for $24.0 \%$ (1130/4705) of all tweets, including 12.1\% (572/4705) that occurred within an hour after the 17:00 PST discussion-topic automessages, and $11.9 \%(558 / 4705)$ that occurred within an hour after the 9:00 PST engagement autofeedback (vs 3.5\% or $163 / 4705 / h$ otherwise, $F(1,88)=69.29$, $p<0.001$; see online supplementary figure S1). However, 50.5\% (2376/4705) of the tweets were directed to the entire group, and 33.5\% (1576/ 4705) were directed to one or more specific members; just $16.0 \%(753 / 4705)$ were directed to the account that sent the automessages.

\section{Predictors of sustained abstinence and tweet volume}

No measured demographic or tobacco use variable interacted significantly with study condition to affect abstinence. As significant main effects, men and participants reporting a resolute abstinence goal at baseline were more likely to achieve sustained abstinence than women and participants with a less resolute abstinence goal (table 3).

Among Tweet2Quit participants, tweet volume related significantly to sustained abstinence $(\mathrm{OR}=1.02$, CI 1.02 to 1.03 , $\mathrm{p}<0.001$ ), with each additional 10 tweets increasing the tweeter's odds of sustained abstinence by $20 \%$ on average. Significant predictors of tweet volume or engagement were posting an image for the Tweet2Quit user profile, tweeting on a mobile phone with texting, tweeting while at work, and having a college degree (table 3 ).

Tweet volume exhibited exponential decline over time $\left(\mathrm{R}^{2}=0.73, \mathrm{p}<0.001\right.$; see online supplementary figure $\left.\mathrm{S} 2\right)$. Notwithstanding, Tweet2Quit participants who reported sustained abstinence, versus not, tweeted longer $(\mathrm{F}(1,63)=13.77$, $\mathrm{p}<0.001)$ and more $(\mathrm{F}(1,63)=25.62, \mathrm{p}<0.001)$. On average, 
Table 1 Participant profile

\begin{tabular}{|c|c|}
\hline Variable & Mean or per cent \\
\hline Age & $35.7(\mathrm{SD}=9.9)$ \\
\hline \multicolumn{2}{|l|}{ Sex } \\
\hline Male & $26.3 \%(42 / 160)$ \\
\hline \multicolumn{2}{|l|}{ Education } \\
\hline College degree or higher & $31.2 \%(50 / 160)$ \\
\hline Some college & $40.0 \%(64 / 160)$ \\
\hline High school degree or less & $28.8 \%(46 / 160)$ \\
\hline \multicolumn{2}{|l|}{ Race or ethnicity } \\
\hline Caucasian non-Hispanic & $88.7 \%(142 / 160)$ \\
\hline African-American & $6.9 \%(11 / 160)$ \\
\hline Hispanic & $4.4 \%(7 / 160)$ \\
\hline \multicolumn{2}{|l|}{ Marital status } \\
\hline Married or partnered & $51.2 \%(82 / 160)$ \\
\hline Divorced or separated & $20.0 \%(32 / 160)$ \\
\hline Never married & $28.8 \%(46 / 160)$ \\
\hline \multicolumn{2}{|l|}{ Employment status } \\
\hline Employed & $68.7 \%(110 / 160)$ \\
\hline Unemployed & $16.2 \%(26 / 160)$ \\
\hline Full-time homemaker & $8.8 \%(14 / 160)$ \\
\hline Student & $6.3 \%(10 / 160)$ \\
\hline \multicolumn{2}{|l|}{ Geographic census region } \\
\hline South & $34.4 \%(55 / 160)$ \\
\hline Midwest & $28.1 \%(45 / 160)$ \\
\hline Northeast & $18.8 \%(30 / 160)$ \\
\hline West & $18.8 \%(30 / 160)$ \\
\hline Cigarettes per day & $18.0(\mathrm{SD}=8.2)$ \\
\hline Years of smoking & $16.8(S D=9.8)$ \\
\hline Fagerström cigarette dependency score & $4.7(S D=2.1)$ \\
\hline Resolute abstinence goal & $67.6 \%(94 / 139)$ \\
\hline Used $1+$ cessation aids in prior quit attempts & $66.0 \%(93 / 141)$ \\
\hline Used nicotine patch & $41.1 \%(58 / 141)$ \\
\hline Used a prescription drug & $39.0 \%(55 / 141)$ \\
\hline Used nicotine gum & $22.0 \%(31 / 141)$ \\
\hline
\end{tabular}

sustained abstainers $(\mathrm{N}=26)$ tweeted 10.5 weeks $(\mathrm{SD}=4.5)$ and posted 115.5 tweets per participant $(\mathrm{SD}=81.7)$, while those who did not report sustained abstinence $(\mathrm{N}=39)$ tweeted
Table 2 Effects for condition on sustained abstinence and treatment usage

\begin{tabular}{|c|c|c|c|}
\hline \multirow[b]{2}{*}{ Outcome } & \multicolumn{2}{|l|}{ Condition } & \multirow[b]{2}{*}{ p Value } \\
\hline & Tweet2Quit & Control & \\
\hline $\begin{array}{l}\text { Sustained abstinence- } \\
\text { primary }\end{array}$ & $40.00 \%(26 / 65)$ & $20.00 \%(14 / 70)$ & 0.017 \\
\hline $\begin{array}{l}\text { Sustained abstinence-- } \\
\text { lost to follow-up } \\
\text { imputed to be smoking }\end{array}$ & $32.50 \%(26 / 80)$ & $17.50 \%(14 / 80)$ & 0.039 \\
\hline Set a quit date & $76.25 \%(61 / 80)$ & $86.25 \%(69 / 80)$ & 0.105 \\
\hline $\begin{array}{l}\text { Number of days patches } \\
\text { used, } 7 \text { days post-quit } \\
\text { date }\end{array}$ & $5.57(S D=2.41)$ & $5.93(S D=1.85)$ & 0.406 \\
\hline $\begin{array}{l}\text { Number of days patches } \\
\text { used, } 30 \text { days post-quit } \\
\text { date }\end{array}$ & $22.29(S D=11.05)$ & $22.96(\mathrm{SD}=8.48)$ & 0.741 \\
\hline $\begin{array}{l}\text { Number of days patches } \\
\text { used, } 60 \text { days post-quit } \\
\text { date }\end{array}$ & $10.32(S D=12.60)$ & $12.84(S D=12.14)$ & 0.305 \\
\hline $\begin{array}{l}\text { Number of smokefree. } \\
\text { gov visits, } 7 \text { days } \\
\text { post-quit date }\end{array}$ & $0.84(S D=1.55)$ & $0.93(S D=1.48)$ & 0.770 \\
\hline $\begin{array}{l}\text { Number of smokefree. } \\
\text { gov visits, } 30 \text { days } \\
\text { post-quit date }\end{array}$ & $2.83(\mathrm{SD}=8.45)$ & $2.21(S D=3.52)$ & 0.637 \\
\hline $\begin{array}{l}\text { Number of smokefree. } \\
\text { gov visits, } 60 \text { days } \\
\text { post-quit date }\end{array}$ & $1.11(S D=4.35)$ & $1.30(S D=3.69)$ & 0.815 \\
\hline
\end{tabular}

6.0 weeks $(\mathrm{SD}=5.0)$ and posted 38.7 tweets per participant $(\mathrm{SD}=39.5)$.

\section{Predictors of study retention}

For the full sample, no measured variable significantly related to study retention, that is, completion of assessments. Among Tweet2Quit participants, two variables related to retention: $88.3 \%(53 / 60)$ who tweeted the group at least once completed the follow-up assessments versus $60.0 \%(12 / 20)$ of non-tweeters $(\mathrm{p}=0.005)$; and $90.7 \%(39 / 43)$ who posted an image for their user profile completed the assessments versus $70.27 \%(26 / 37)$ of non-posters $(\mathrm{p}=0.020)$.

Table 3 Predictors of sustained abstinence and tweet volume

\begin{tabular}{|c|c|c|c|c|c|c|}
\hline & \multicolumn{3}{|c|}{ Relationship to sustained abstinence* $† \ddagger$} & \multicolumn{3}{|c|}{ Intervention only, relationship to tweet volume* } \\
\hline & OR & $\mathrm{Cl}$ & p Value & $\boldsymbol{\beta}$ & $\mathrm{Cl}$ & p Value \\
\hline Age & 1.01 & 0.93 to 1.11 & 0.776 & 1.36 & -0.76 to 3.47 & 0.210 \\
\hline Sex: male & 1.25 & 1.03 to 1.52 & 0.027 & -0.50 & -41.68 to 40.69 & 0.981 \\
\hline Education: college degree or higher & 0.97 & 0.83 to 1.13 & 0.686 & 14.40 & 13.69 to 69.11 & 0.003 \\
\hline Marital status: married/partnered & 1.16 & 0.98 to 1.37 & 0.092 & -24.22 & -65.40 to 16.95 & 0.249 \\
\hline Employment status: employed & 0.94 & 0.84 to 1.05 & 0.239 & -16.86 & -59.83 to 26.10 & 0.442 \\
\hline Cigarettes per day at baseline & 1.01 & 0.99 to 1.02 & 0.512 & 2.30 & -1.93 to 6.53 & 0.287 \\
\hline $\begin{array}{l}\text { Resolute abstinence goal } \\
\text { Intervention participants only }\end{array}$ & 1.16 & 1.06 to 1.27 & 0.001 & -15.27 & -61.86 to 31.32 & 0.521 \\
\hline Posted image for Tweet2Quit profile & 1.35 & 0.59 to 3.07 & 0.478 & 51.90 & 5.39 to 98.41 & 0.029 \\
\hline Tweeted on mobile phone with texting & 1.19 & 0.43 to 3.30 & 0.737 & 33.73 & 18.75 to 48.71 & 0.001 \\
\hline Tweeted at work & 1.12 & 0.34 to 3.63 & 0.856 & 40.06 & 21.75 to 58.37 & 0.001 \\
\hline Tweet volume & 1.02 & 1.02 to 1.03 & 0.001 & - & - & - \\
\hline
\end{tabular}

*Based on multivariate models.

†No interactions with condition (intervention vs control), $p>0.289$.

¥Sustained abstinence was recorded if a participant responded at 7, 30 and 60 days, and consistently reported not smoking for the prior 7 days. 


\section{DISCUSSION}

Our social network intervention, Tweet2Quit, doubled the odds of self-reported sustained smoking abstinence to 60 days follow-up, when added to the usual care of nicotine patches and a quit-smoking website. Moreover, engagement in Tweet2Quit was high with most participants tweeting for an extended duration; and engagement related to abstinence. Because smokers were randomly assigned to Tweet2Quit versus control, the evidence suggests a causal effect for Tweet2Quit on abstinence. Tweet2Quit did not affect nicotine patch use or use of the quit-smoking website, so the mechanism of action seems to be tweeting and social network support from the groups.

\section{Contributions to the literature}

This is one of the first experimental studies to examine Twitter as a delivery mechanism for a health prevention intervention. Prior observational research found that existing Twitter and Facebook self-help groups were short-lived, ${ }^{2}$ and the content was often questionable. ${ }^{27}$ Hence, we customised Twitter using two promising ideas from past research. Peer-support studies suggested that smokers might benefit from buddies they can quit with, ${ }^{19-21}$ and technology studies indicated smokers might benefit from automated, fixed schedule text messages from experts. ${ }^{23-28}$ We combined these two approaches in Tweet2Quit and our results are promising, though further research is needed for replication and extension beyond short-term outcomes.

\section{Clinical implications}

Our results have implications for the utilisation of social networks for clinical interventions. Key features here were the formation of private self-help groups, using an intimate group size of about 20 people, setting fixed start and end dates, using a limited-duration intervention, and sending out autocommunications including daily discussion topics to the group and daily feedback to each individual on their prior $24 \mathrm{~h}$ engagement.

\section{Limitations and future research}

In this initial Tweet2Quit study, our abstinence measure was short term (60 days), measured before intervention end, and

\section{What this paper adds}

- Social network sites allow people who are geographically separated but connected by interests to communicate interactively, at virtually no cost, often in real time and on mobile devices.

- However, the potential for social network sites to host self-help groups for quitting smoking has not yet been realised because, generally, engagement is too low, and paid group facilitators are too costly.

- This study finds that a 100-day social network-based intervention can significantly improve the odds of smoking abstinence out to 60 days.

- The intervention is called Tweet2Quit, and it employs a two-pronged approach: (1) using Twitter, it sets up small, private, virtual self-help groups of smokers who are motivated to quit and (2) it sends out daily automated messages posing treatment-relevant questions written by experts for smokers to discuss.

- The intervention is very low cost and highly scalable, and the findings hold promise for delivering low-cost tobacco treatments globally. self-reported. Planned next steps are a larger trial with longer follow-up and bioconfirmed abstinence. Very few eHealth studies have used bioconfirmed abstinence because of difficulties in obtaining biosamples, ${ }^{43}$ and research indicating self-reports can provide accurate estimates of smoking status. ${ }^{44}$ We also used a small sample that was largely non-Hispanic Caucasian and female. This may be attributable to recruitment which emphasised nicotine patches and social support as incentives. We also screened for daily Facebook use, because in our pilot, this predicted engagement. While consistent with personalised or precision medicine, ${ }^{45}$ this limits participation, although Facebook reports over 968 million daily users as of June 2015 (about $73 \%$ of online adults). ${ }^{10}$

Consistent with many prior smoking cessation trials with nicotine replacement, we observed that men were significantly more likely to quit than women. ${ }^{46}$ However, both genders were highly engaged in Tweet2Quit. In future research, we hope to examine why women were less successful quitters and try to improve their odds. We are also adapting our intervention for other disease prevention efforts, for example, promoting physical activity in women with heart disease.

Acknowledgements The authors thank Doug Calder and Howard Liu for their research assistance and the Bonnie J Addario Lung Cancer Foundation for its support.

Contributors CP and JJP led research design, intervention design and implementation, assessment design and implementation, data analysis, and write-up. KD assisted primarily with research design, data analysis and write-up. CML assisted primarily with intervention design, assessment design and write-up. CP led subject recruitment and data collection and entry.

Funding This research was supported by an NIH R34 Innovation grant DA030538.

Competing interests JJP is serving as an expert witness in litigation against tobacco companies and has consulted for Pfizer which makes cessation medications.

Ethics approval University of California Irvine IRB HS\# 2010-7990, approval granted 19 January 2012.

Provenance and peer review Not commissioned; externally peer reviewed.

Open Access This is an Open Access article distributed in accordance with the Creative Commons Attribution Non Commercial (CC BY-NC 4.0) license, which permits others to distribute, remix, adapt, build upon this work non-commercially, and license their derivative works on different terms, provided the original work is properly cited and the use is non-commercial. See: http://creativecommons.org/ licenses/by-nc/4.0/

\section{REFERENCES}

1 Boyd DM, Ellison NB. Social network sites: definition, history, and scholarship. J Comput-Mediat Commun 2007;13:210-30.

2 Prochaska JJ, Pechmann C, Kim R, et al. Twitter=quitter? An analysis of Twitter quit smoking social networks. Tob Control 2012;21:447-9.

3 Young SD, Cumberland WG, Nianogo R, et al. The HOPE social media intervention for global HIV prevention in Peru: a cluster randomised controlled trial. Lancet HIV 2015;2:e27-32.

4 Young SD, Holloway I, Jaganath D, et al. Project HOPE: online social network changes in an HIV prevention randomized controlled trial for African American and Latino men who have sex with men. Am J Public Health 2014;104:1707-12.

5 Young SD, Cumberland WG, Lee SJ, et al. Social networking technologies as an emerging tool for HIV prevention: a cluster randomized trial. Ann Intern Med 2013;159:318-24.

6 Griffiths F, Cave J, Boardman F, et al. Social networks - the future for health care delivery. Soc Sci Med 2012;75:2233-41.

7 Myslin M, Zhu SH, Chapman W, et al. Using Twitter to examine smoking behavior and perceptions of emerging tobacco products. J Med Internet Res 2013;15:e174.

8 Gruzd A, Haythornthwaite C. Enabling community through social media. J Med Internet Res 2013;15:e248.

9 Kennedy TLM, Smith A, Wells AT, et al. Networked families. Pew Internet \& American Life Project, 2008:1-36.

10 Duggan M, Smith A. 42\% of online adults use multiple social networking sites, but Facebook remains the platform of choice. Pew Research Center, 2013:1-18.

11 Stoddard JL, Augustson EM, Moser RP. Effect of adding a virtual community (bulletin board) to smokefree.gov: randomized controlled trial. J Med Internet Res 2008; 10:e53. 
12 Danaher BG, Boles SM, Akers L, et al. Defining participant exposure measures in Web-based health behavior change programs. J Med Internet Res 2006;8:e15.

13 An LC, Schillo BA, Saul JE, et al. Utilization of smoking cessation informational, interactive, and online community resources as predictors of abstinence: cohort study. J Med Internet Res 2008;10:e55.

14 Arguello J, Butler BS, Joyce $E$, et al. Talk to me: foundations for successful individual-group interactions in online communities. Proceedings of the SIGCHI Conference on Human Factors in Computing Systems. Montreal, QC, Canada: ACM, 2006.

15 Burke $\mathrm{M}$, Joyce $\mathrm{E}$, Kim $\mathrm{T}$, et al. Introductions and requests: rhetorical strategies that elicit response in online communities. In: Steinfield C, Pentland BT, Kim T, Ackerman M, Contractor N, eds. Communities and technologies 2007. London, UK Springer, 2007:21-39.

16 Burke M, Kraut R, Marlow C. Social capital on Facebook: differentiating uses and users. SIGCHI Conference on Human Factors in Computing Systems; Vancouver, BC, Canada, 2011:959-68.

17 Joyce $E$, Kraut RE. Predicting continued participation in newsgroups. J Comput-Mediat Commun 2006;11:723-47.

18 Ren $Y$, Kraut R, Kiesler S. Applying common identity and bond theory to design of online communities. Organ Stud 2007;28:377-408.

19 May S, West R. Do social support interventions ("buddy systems") aid smoking cessation? A review. Tob Control 2000;9:415-22.

20 May $S$, West $R$, Hajek $P$, et al. Randomized controlled trial of a social support ('buddy') intervention for smoking cessation. Patient Educ Couns 2006;64:235-41.

21 West R, Edwards M, Hajek P. A randomized controlled trial of a "buddy" system to improve success at giving up smoking in general practice. Addiction 1998;93:1007-11.

22 Fiore MC. Treating tobacco use and dependence: 2008 update. U. S. Department of Health and Human Services, 2008:1-256.

23 Free $C$, Whittaker $\mathrm{R}$, Knight $\mathrm{R}$, et al. Txt2stop: a pilot randomised controlled trial of mobile phone-based smoking cessation support. Tob Control 2009;18:88-91.

24 Brendryen $\mathrm{H}$, Kraft P. Happy ending: a randomized controlled trial of a digital multi-media smoking cessation intervention. Addiction 2008;103:478-84; discussion 485-6.

25 Free C, Knight R, Robertson S, et al. Smoking cessation support delivered via mobile phone text messaging (txt2stop): a single-blind, randomised trial. Lancet 2011;378:49-55.

26 Lenert L, Muñoz RF, Perez JE, et al. Automated e-mail messaging as a tool for improving quit rates in an internet smoking cessation intervention. J Am Med Inform Assoc 2004;11:235-40.

27 Kong G, Ells DM, Camenga DR, et al. Text messaging-based smoking cessation intervention: a narrative review. Addict Behav 2014;39:907-17.

28 Spohr SA, Nandy R, Gandhiraj D, et al. Efficacy of SMS text message interventions for smoking cessation: a meta-analysis. J Subst Abuse Treat 2015;56:1-10.
29 Willemsen $M C$, Wiebing $M$, van Emst $A$, et al. Helping smokers to decide on the use of efficacious smoking cessation methods: a randomized controlled trial of a decision aid. Addiction 2006;101:441-9.

30 Brown RA, Burgess ES, Sales SD, et al. Reliability and validity of a smoking timeline follow-back interview. Psychol Addict Behav 1998;12:101-12.

31 Prochaska JJ, Hall SE, Delucchi K, et al. Efficacy of initiating tobacco dependence treatment in inpatient psychiatry: a randomized controlled trial. Am J Public Health 2014; 104:1557-65.

32 Pechmann C, Pan L, Delucchi K, et al. Development of a twitter-based intervention for smoking cessation that encourages high-quality social media interactions via automessages. J Med Internet Res 2015;17:e50.

33 Shi X, Adamic LA, Strauss MJ. Networks of strong ties. Physica A 2007;378:33-47.

34 Trusov M, Bodapati AV, Bucklin RE. Determining influential users in internet social networks. J Mark Res 2010;47:643-58.

35 Anderson JE, Jorenby DE, Scott WJ, et al. Treating tobacco use and dependence: an evidence-based clinical practice guideline for tobacco cessation. Chest 2002;121:932-41.

36 Xiao Z, Guo L, Tracey J. Understanding instant messaging traffic characteristics. Distributed Computing Systems, 27th International Conference; Toronto, ON, 2007:1-51.

37 Hall SM, Havassy BE, Wasserman DA. Effects of commitment to abstinence, positive moods, stress, and coping on relapse to cocaine use. J Consult Clin Psychol 1991;59:526-32.

38 Hall SM, Havassy BE, Wasserman DA. Commitment to abstinence and acute stress in relapse to alcohol, opiates, and nicotine. J Consult Clin Psychol 1990;58:175-81.

39 Fagerström K. Determinants of tobacco use and renaming the FTND to the Fagerström test for cigarette dependence. Nicotine Tob Res 2012;14:75-8.

40 Heatherton TF, Kozlowski LT, Frecker RC, et al. The Fagerström test for nicotine dependence: a revision of the Fagerström tolerance questionnaire. $\mathrm{Br} J$ Addict 1991;86:1119-27.

41 The Cochrane Collaboration. Key review summaries. Cochrane Tobacco Addiction. 2015. http://tobaccocochraneorg/resources (accessed 13 Oct 2015).

42 Cahill K, Stevens S, Perera R, et al. Pharmacological interventions for smoking cessation: an overview and network meta-analysis. Cochrane Database Syst Rev 2013;5:1-50

43 Civljak M, Stead LF, Hartmann-Boyce J, et al. Internet-based interventions for smoking cessation (Review). Cochrane Database Syst Rev 2013;7:1-75.

44 Wong SL, Shields M, Leatherdale S, et al. Assessment of validity of self-reported smoking status. Health Rep 2012;23:47-53.

45 Collins FS, Varmus $\mathrm{H}$. A new initiative on precision medicine. N Engl J Med 2015:372:793-5.

46 Perkins KA, Scott J. Sex differences in long-term smoking cessation rates due to nicotine patch. Nicotine Tob Res 2008;10:1245-51. 